\title{
As regras da prática pedagógica no currículo de Ciências na educação de jovens e adultos: uma leitura baseada em Basil Bernstein
}

\author{
Débora Silveira Barros Bezerra ${ }^{1}$ \\ http://orcid.org/0000-0002-4485-461X \\ Benedito Eugenio ${ }^{2}$ \\ http://orcid.org/0000-0002-5781-764X
}

\begin{abstract}
Resumo
Este artigo tem por objetivo identificar as regras da prática pedagógica presentes no discurso pedagógico e materializado no currículo de Ciências na sala de aula da EJA - Tempo Juvenil. A pesquisa teve como principal referencial teórico os estudos sociológicos de Basil Bernstein (1996), sobre o discurso pedagógico, e os trabalhos desenvolvidos pelo Grupo de Estudos Sociológicos da Sala de Aula (ESSA). Esta investigação é de caráter qualitativo, do tipo estudo de caso. Para o levantamento dos dados, utilizamos os seguintes procedimentos: a observação participante; gravação em áudio das aulas; anotações em diário de campo. Os resultados apontam para as diversas relações sociológicas que caracterizam as dimensões instrucional e reguladora da prática pedagógica do professor de Ciências no Programa Tempo Juvenil.
\end{abstract}

Palavras-Chave: Basil Bernstein; Regras da Prática; Educação de jovens e adultos.

\begin{abstract}
This article aims to identify the rules of pedagogical practice present in the pedagogical and materialized discourse in the curriculum of science in the classroom of youth and adult education- Youth Time. The research had as its main theoretical reference the sociological studies of Basil Bernstein (1996) on pedagogical discourse and the work developed by the Sociological Studies Group of the Classroom (ESSA). This research is of qualitative character, being a case study its research method. For data collection, we used the following techniques: participant observation; audio recording of the classes; notes in a field diary. The results point to the various sociological relations that characterize the instructional and regulatory dimensions of the pedagogical practice of the science teacher in the Youth Time Program.
\end{abstract}

Keywords: Basil Bernstein; Practice Rules; Youth and Adult Education.

\footnotetext{
Licenciada em Ciências Biológicas e Mestre em Ensino pela Universidade Estadual do Sudoeste da Bahia (UESB). Professora de Ciências e Biologia na Rede Estadual de Ensino da Bahia. E-mail: debora.bezerra@enova.educacao.ba.gov.br

2 Doutor em Educação pela UNICAMP. Professor da Universidade Estadual do Sudoeste da Bahia e do Programa de Pós-graduação em Ensino (PPGEN/Uesb). E-mail: dodoeugenio@gmail.com
} 
Introdução

O processo de juvenilização é um fenômeno cada vez mais comum na Educação de Jovens e Adultos, conforme observado por Leão (2007). Esse autor alerta para a importância de se compreender os sujeitos matriculados nessa modalidade de ensino, suas representações e a forma de acolhimento desses jovens no ambiente escolar.

Leão (2007) apresenta uma reflexão sobre a necessidade de se buscar práticas pedagógicas que superem o desejo de assistir e tutelar a juventude, além da necessidade de afastar a ideia de que os jovens não se interessam e não demandam por escolarização. Para o autor, “[...] a EJA pode ser uma alternativa de escolarização na qual os jovens pobres tenham acesso a experiências significativas e possam desenvolver todas as potencialidades dessa fase da vida como sujeitos autônomos e de direitos" (LEÃO, 2007, p.74).

Na Bahia, em 2013, o governo do estado criou uma proposta pedagógica conhecida como Tempo Juvenil, com o objetivo de garantir aos adolescentes de 15 a 17 anos que não concluíram o Ensino Fundamental, o direito à formação em programas e projetos específicos a essa etapa da Educação Básica (BAHIA, 2013).

O programa Tempo Juvenil foi implementado em quatro escolas-piloto do município de Vitória da Conquista, na Bahia, no ano de 2014. De acordo com a proposta pedagógica, o currículo para o Programa deve responder ao protagonismo juvenil, buscando valorizar práticas dialógicas e emancipatórias.

Neste artigo, analisamos a prática pedagógica de um docente ao trabalhar com o currículo de Ciências em uma turma dos anos finais do Ensino fundamental. A pesquisa teve como principal referencial teórico os estudos sociológicos de Basil Bernstein (1996) sobre o discurso pedagógico, acrescido das contribuições das pesquisas desenvolvidas pelo Grupo de Estudos Sociológicos da Sala de Aula (ESSA), vinculado ao Centro de Investigação em Educação da Faculdade de Ciências da Universidade de Lisboa.

Segundo Galian (2012), os principais estudos do grupo ESSA estão voltados ao ensino de Ciências e suas pesquisas relacionadas a textos curriculares (programas e manuais escolares ${ }^{3}$ ), práticas pedagógicas, relações entre discursos, sujeitos e espaços. Esse grupo tem criado indicadores que nos auxiliam a caracterizar a prática pedagógica docente e identificar elementos que evidenciem a possibilidade de uma pedagogia mista no interior do currículo na sala de aula.

De acordo com Morais e Neves (2003, p. 30), a Pedagogia Mista:

\footnotetext{
Constitui uma possibilidade oferecida pela linguagem de descrição, derivada da teoria de Bernstein, que permite a distinção de aspectos específicos dos contextos sociais da sala de aula, introduzindo uma dimensão de grande rigor na investigação das práticas pedagógicas dos professores.
}

A conclusão a que o grupo tem chegado é que a Pedagogia Mista pode promover uma prática favorável à aprendizagem das crianças de origens sociais menos favorecidas e deve mesclar determinadas características, tais como: fracas fronteiras entre espaços do professor e dos alunos; relações comunicativas abertas entre professoraluno e aluno-aluno; critérios de avaliação explícitos; fraca ritmagem; fortes relações intradisciplinares; elevado nível de exigência conceitual e elevado nível de competência investigativa (PIRES; MORAIS; NEVES, 2004).

Neste artigo, apresentamos os resultados de uma pesquisa que objetivou descrever e analisar as regras da prática pedagógica presentes no currículo de Ciências de uma turma dos anos finais do ensino fundamental da Educação de Jovens e Adultos.

Em Portugal, manuais escolares são os livros didáticos. 


\title{
Fundamentação teórica
}

Basil Bernstein foi um importante sociólogo inglês, autor de uma teoria relacionada a códigos sociolinguísticos, os quais permitem a descrição detalhada de variadas situações presentes no currículo em sala de aula. Conceitos de sua teoria vêm sendo empregados por pesquisadores de diferentes questões do campo educacional, a exemplo do currículo, políticas educacionais, formação de professores, análise de materiais curriculares, dentre outros. Um dos focos do trabalho de Bernstein (1996) consistiu em analisar as relações pedagógicas e os pressupostos de classe social dessas práticas. Segundo Santos (2003, p. 17), “A partir do conceito de código, baseado nos códigos linguísticos e estabelecendo analogias entre este e os processos educacionais, constrói sua teoria sobre o processo de constituição dos conhecimentos escolares".

Bernstein produziu uma teoria que evidencia como a escola produz desigualdades por meio das diferenças de desempenho. Para isso, analisa o aparelho escolar internamente empregando uma teoria que possibilita a descrição minuciosa das situações de ensino e aprendizagem presentes no currículo.

Conforme Santos (2003, p.25):

\begin{abstract}
Ao descrever os processos de comunicação pedagógica, ele mostra como a escola trabalha e, dessa forma, explicita como as diferenças que ocorrem no desempenho dos alunos não estão apenas relacionadas à estrutura social, mas também com a própria forma como estas hierarquias se inscrevem ou são elementos constituintes do aparelho pedagógico. Sua teoria não contém uma proposta de mudança ou alternativas para a transformação da educação. Contudo, ao buscar desvendar elementos intrínsecos ao aparelho escolar, que condicionam a produção e recepção diferenciada de mensagens ou de discursos, o autor abre caminho para o entendimento mais profundo de como as desigualdades educacionais são produzidas e justificadas.
\end{abstract}

A teoria sociológica bernsteiniana tem sido empregada em diversos estudos, principalmente naqueles envolvendo o ensino de Ciências e Matemática, a exemplo de Silva; Souza e Santos (2018), Eugenio (2017), Pires (2001), Gallian (2009), Diniz (2017) e Grilo (2014). A linguagem de descrição propiciada pelos conceitos de discurso pedagógico, classificação e enquadramento contribui para compreender diferentes dimensões do currículo, mas também da formação docente, dos materiais curriculares, dos livros didáticos e das políticas educacionais.

Conforme aponta Silva et al (2018, p.72):

\begin{abstract}
A teoria sobre o discurso pedagógico de Basil Bernstein se destaca ao relacionar os microcontextos da educação, como o espaço da sala de aula, com os contextos sociais mais amplos. Por meio dos conceitos de classificação e enquadramento, Bernstein propõe verificar como as categorias sociológicas de poder e de controle, respectivamente, atuam sobre as práticas pedagógicas desenvolvidas no interior das escolas. Para este autor, a distribuição do poder e do controle se origina na divisão social do trabalho e, por meio desta, influencia as relações entre as classes sociais. De acordo com sua teoria, o poder e o controle se traduzem em princípios de comunicação na relação pedagógica.
\end{abstract}

Para Bernstein (1996), toda relação pedagógica consiste em três regras:

1. Regras hierárquicas (Também conhecidas como regulativas): É a regra dominante da prática pedagógica, na qual o transmissor (professor) aprende a ser transmissor e o adquirente (aluno) aprende a ser adquirente. 
2. Regras de sequenciamento (Instrucionais ou discursivas): Na relação pedagógica, a transmissão ocorre de forma gradual através de uma progressão do que vem antes e o que vem depois. Dessa forma, para Bernstein (1996), se há progressão, há regras de sequenciamento. Toda prática deve ter regras de sequenciamento e essas regras de sequenciamento implicarão em regras de compassamento (ou ritmagem). Bernstein (1996, p.97) define compassamento como "[...] a velocidade esperada de aquisição das regras de sequenciamento, isto é, quanto se tem que aprender num dado espaço de tempo". Essencialmente é o tempo permitido para se cumprir as regras de sequenciamento.

3. Regras Criteriais (Regras Instrucionais ou discursivas): Por último, o autor determina que existem critérios que são esperados para que o adquirente assuma e aplique às suas próprias práticas. De acordo com Bernstein (1996, p.97), “[...] os critérios permitem que o adquirente compreenda o que conta como uma comunicação, uma relação social ou uma posição legítima ou ilegítima”.

Essas regras são importantes para caracterizarmos, por meio da descrição detalhada de episódios em sala de aula, a prática pedagógica presente no currículo, conforme veremos no decorrer deste artigo.

\section{Metodologia}

Esta pesquisa se insere na modalidade qualitativa, do tipo estudo de caso. Buscamos “[...] a compreensão do comportamento a partir dos sujeitos da investigação", que é representado aqui principalmente pelo professor de Ciências e sua relação com os alunos da etapa 4 do Programa Tempo Juvenil (BOGDAN; BIKLEN, 1994, p.16).

A investigação foi realizada na Escola do Bosque ${ }^{4}$, instituição educacional da rede pública estadual do município de Vitória da Conquista, Bahia. Esta pesquisa é do tipo estudo de caso. Analisamos a prática pedagógica do professor de Ciências em seu contexto regulador. Para isso, utilizamos a observação com a gravação em áudio de 10 aulas, com 50 minutos cada, na turma 4A da EJA-Tempo Juvenil, no período de abril a julho de 2018.

Além das observações, desenvolvemos um diário de campo para o registro de ocorridos, impressões e reflexões das aulas. Aplicamos também um questionário socioeconômico e cultural com os alunos, pois acreditamos - como apontado por Morais (1993, p. 128) - que “[...] a prática do professor é fortemente influenciada pela composição social da turma".

O discurso pedagógico ocorre com a inter-relação de dois discursos especializados: o discurso instrucional e o discurso regulador. O primeiro especifica qual conhecimento deve ser transmitido, representando o quê da prática pedagógica, e o discurso regulador especifica como o conhecimento deve ser transmitido (MAINARDES, 2007).

Os conceitos de classificação e enquadramento são muito utilizados na pesquisa, porque são conceitos-chave para o entendimento da teoria de Bernstein, uma vez que expressam relações de poder (classificação) e controle (enquadramento).

4 Escola do Bosque é um nome fictício que escolhemos para a escola em que realizamos a pesquisa. 
A classificação (C) refere-se ao grau de manutenção entre categorias (professores, alunos, espaços, conteúdos de aprendizagem, escola, família, etc.) e o enquadramento (E), às relações de comunicação entre categorias no contexto da relação pedagógica. De acordo com Pires, Morais e Neves (2004), o enquadramento está relacionado tanto às regras discursivas do contexto instrucional quanto às regras hierárquicas do contexto regulador. No contexto instrucional, o enquadramento entre sujeitos se refere ao controle que eles têm na seleção, sequência, ritmagem e nos critérios de avaliação.

O grupo ESSA construiu instrumentos para esses dois contextos, contendo indicadores para as relações entre espaços, discursos e sujeitos. Os instrumentos serviram para nos orientar em relação à análise dos registros das aulas observadas. Para a caracterização da prática pedagógica, valemo-nos desses instrumentos de análise para identificar e analisar os graus de enquadramento e classificação da prática pedagógica do professor Antônio. ${ }^{5}$ A escala varia entre muito forte $(\mathrm{C}++, \mathrm{E}++)$ e muito fraco (C--, E--).

Por meio desta metodologia, foi possível descrever, de forma detalhada, as diversas relações sociológicas que caracterizam a dimensão reguladora da prática pedagógica do professor de Ciências no Programa Tempo Juvenil, conforme descrito nos resultados e discussões.

A pesquisa foi submetida e aprovada pelo Comitê de Ética em Pesquisa (CEP/UESB) sob o número CAAE 88166218.1 .0000 .0055

\section{Resultados e discussões}

\section{O professor de Ciências e as suas aulas}

O professor Antônio é formado em Ciências Biológicas e Pós-Graduado em Ciências Ambientais pela Universidade Estadual do Sudoeste da Bahia- UESB. Ele trabalha como professor regente na Escola do Bosque há mais de 10 anos e está há um ano e meio no Programa Tempo Juvenil. Antônio considera a EJA-Tempo Juvenil como um bom programa, por "[...] resgatar meninos que não podem ser inseridos no currículo de outras turmas do regular por conta da idade".

Com relação aos estudantes da EJA-Tempo Juvenil, o professor os considera com baixa estima, por não terem concluído o curso e não conseguirem acompanhar os colegas de sua idade. Sendo assim, o docente acredita ser necessário um ensino diferenciado e compacto (dois anos em um) para esses adolescentes.

Para o professor Antônio, os problemas encontrados para se trabalhar no Programa estão relacionados à falta de material e à estrutura física da escola. Ele avalia o Tempo Juvenil como positivo, apesar dessas dificuldades. O docente conhece a proposta do programa, mas considera que o tempo para o planejamento das aulas, na proposta, é insuficiente. Então, ele planeja suas aulas fora da escola, pois esta não oferece recursos como computador com internet, livros para pesquisa, impressão.

Sobre os critérios utilizados para selecionar os conteúdos ensinados para o Tempo Juvenil, o professor relatou que ele inicia suas aulas com temas "mais fáceis" para atrair os alunos; depois vai aprofundando o conteúdo. Entretanto, Antônio diz não exigir em avaliação os conteúdos mais difíceis como exige das outras turmas que não fazem parte do Programa e se encontram no sistema seriado.

\footnotetext{
Nome fictício escolhido para o professor de Ciências.
} 
Quando questionado sobre o que considera importante no aprendizado de seus alunos, o docente caracterizou a sua prática pedagógica como tradicional: "Eu gosto de ser tradicionalista, eu gosto do conteúdo, porque eu acho que o conteúdo vai dar a base, então quando você estudar o átomo você vai entender o conceito para desenvolver o raciocínio, eu funciono assim, então eu sou conteudista e tradicionalista neste sentido".

Na visão do professor, a disciplina de Ciências é interdisciplinar, mas a dificuldade em ensiná-la é a falta de leitura e domínio das ciências exatas, da matemática, por parte dos alunos. Declara ele, ainda, que tem mais dificuldade em trabalhar exatamente os conteúdos que envolvem a interdisciplinaridade porque seus alunos não conseguem estabelecer essa conexão com as demais disciplinas.

Com relação aos critérios que o docente estabelece para definir os conteúdos mais relevantes para a etapa 4, o professor afirma:

\begin{abstract}
O objetivo era colocar tudo, de preferência pegar o livro do primeiro ano e começar a primeira unidade para eles, mas isso é uma utopia, não existe. Então, meu primeiro pensamento quando vou trabalhar o conteúdo com eles é sentir a turma, se for para passar o ano todo vendo um único conteúdo a gente vai trabalhar um único conteúdo com eles, mas a gente tenta ir aprofundando, seguindo o conteúdo. É um sentimento de pertencimento conteudista da turma, então a minha preocupação é se a turma aprendeu, vamos seguir, se não, vamos ficar aqui nessa ciranda girando e girando até entender o tempo deles. Chega uma hora que ninguém aguenta mais falar de átomo, vamos para frente, mas a preocupação é o entendimento máximo da turma e aí tem a sensibilidade de perceber que a turma pode ir além, então nós vamos indo, agora mesmo estou apostando.
\end{abstract}

O Tempo Juvenil conta com um livro didático para cada disciplina do programa, sendo um único volume por disciplina para as duas etapas - a etapa 3 (equivalente aos $6^{\circ}$ e $7^{\circ}$ anos) e a etapa 4 (equivalente aos $8^{\circ}$ e $9^{\circ}$ anos). Em nenhum momento das observações o professor fez uso do livro na etapa 4. De acordo com sua avaliação sobre o material:

É um livro focado para as regiões sul e sudeste, principalmente a sudeste, São Paulo, Minas Gerais e Rio de Janeiro. São livros que tem tudo a ver com a região deles lá, se for falar de um rio, é o Tietê. Se for falar de uma enchente, é a de um bairro tal, coisa que a gente não tem aqui no nosso município. E o livro da EJA por ser um livro mais enxuto neste sentido, porque ele tem que ter o conteúdo de dois anos em um é um volume pequeno, tem que ser barato se não o governo não compra. Então eles enxugam demais o conteúdo e quando tem o conteúdo é com essa sistemática de outra cidade, de outros estados.

Sobre a avaliação do percurso dos alunos no Tempo Juvenil, o docente relatou que faz teste, prova e avalia o caderno. Para ele, “[...] o caderno é indispensável, porque é por ali que eu vejo se ele está acompanhando as aulas". Como na EJA são utilizados conceitos e não notas de 0 a 10 para avaliar os alunos, o professor Antônio faz uma conversão das notas para conceitos no relatório final da unidade.

\title{
Caracterização da Prática do Professor em relação ao Discurso Regulador
}

Para a análise das relações entre professor-aluno, nas Regras Hierárquicas que se estabeleceram nas aulas observadas, foram selecionados os seguintes indicadores: "na relação de comunicação entre professor-aluno", "quando os alunos fazem perguntas" e "perante os comportamentos não legítimos", conforme apresentados nos quadros 1,2 e 3. 


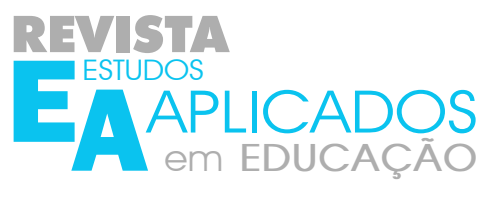

Quadro 1 - Contexto Regulador (DR)-Regras hierárquicas na relação comunicação professor-aluno

\begin{tabular}{|c|c|c|c|c|c|}
\hline \multicolumn{6}{|c|}{$\begin{array}{l}\text { Contexto regulador (DR) - Regras hierárquicas } \\
\text { Relação entre sujeitos: professor-aluno }\end{array}$} \\
\hline & Indi & $\mathbf{E}++$ & $\mathbf{E}+$ & E- & E- - \\
\hline & $\begin{array}{l}\text { Na relação de } \\
\text { comunicação }\end{array}$ & $\begin{array}{c}\text { O professor } \\
\text { polariza o discurso, } \\
\text { sem permitir a } \\
\text { intervenção dos } \\
\text { alunos. }\end{array}$ & $\begin{array}{l}\text { O professor polariza } \\
\text { a comunicação, } \\
\text { mas permite a } \\
\text { intervenção pontual } \\
\text { dos alunos a qualquer } \\
\text { momento, sem alterar } \\
\text { o seu discurso. }\end{array}$ & $\begin{array}{l}\text { Privilegia uma } \\
\text { relação dialógica de } \\
\text { comunicação com } \\
\text { os alunos. }\end{array}$ & $\begin{array}{l}\text { Privilegia uma } \\
\text { relação sempre } \\
\text { dialógica de } \\
\text { comunicação } \\
\text { com os alunos, } \\
\text { permitindo troca de } \\
\text { conhecimentos entre } \\
\text { os dois lados. }\end{array}$ \\
\hline $\begin{array}{l}2 . \\
3 .\end{array}$ & \multicolumn{5}{|c|}{$\begin{array}{l}\text { Episódio } 1 \text { do dia 10/04/2018 } \\
\text { Professor: Vamos começar estudando sobre as células eucarióticas. São as células que a gente tem no nosso } \\
\text { organismo, no organismo humano. Então, o que é uma célula eucariótica? Está aí bem claro, né? (aponta para o slide). } \\
\text { São todas as células cujos constituintes do núcleo encontram-se separados do resto da célula por uma membrana, a } \\
\text { membrana nuclear, ou carioteca, é o mesmo nome, membrana nuclear, ou carioteca. Isso aí é a definição de célula } \\
\text { eucariótica. } \\
\text { Aluno: O que é uma carioteca? } \\
\text { Professor: Diga. O que é uma carioteca? O que é uma célula eucariótica? É uma célula que possui núcleo } \\
\text { individualizado, compartilhado, guardado. Ok? Estão copiando, né? } \\
\text { Professor: Pode passar o slide, gente? Elas se dividem em células eucarióticas vegetais e animais, a gente vai ver por } \\
\text { cada estrutura que tem lá na célula vegetal e animal... } \\
\text { Professor: Bom, isso aqui vocês já sabem de cor e salteado, de trás para frente, de frente para trás, que está falando } \\
\text { em relação ao número de células que os seres vivos podem ser, ou eles são unicelular. O que é unicelular? } \\
\text { Alunos: Única célula } \\
\text { Professor: O organismo todo é dentro de uma célula só, acabou... ou eles são pluricelular. Para unicelular, ele colocou } \\
\text { aqui (aponta para os slides): seres vivos formados por uma única célula... O exemplo aí são bactérias, cianobactérias, } \\
\text { algas unicelulares, os fungos e os protozoários [...]. }\end{array}$} \\
\hline
\end{tabular}

Fonte: Pesquisa direta da autora, 2018.

As Regras Hierárquicas regulam as relações sociais dentro da sala de aula. De acordo com Bernstein (1996, p.97), elas estabelecem as condições para a ordem, o caráter e os modos de comportamento. Podemos observar no indicador "Na relação de comunicação" que o professor Antônio permite que seus alunos the façam perguntas enquanto explica o conteúdo. Entretanto, essa interferência não afeta o seu discurso. Nesse episódio, o aluno pergunta sobre a carioteca, esperando que o professor lhe explicasse melhor aquele conceito não familiar ao seu vocabulário, e o professor responde apenas repetindo a informação de forma sucinta, sem alterar o planejado que estava escrito nos slides. O docente polariza a comunicação na relação entre professor-aluno e, dessa forma, classificamos sua prática pedagógica com um grau de enquadramento forte $(\mathrm{E}+)$.

Podemos também verificar, ao longo das observações, uma fronteira muito nítida entre o espaço do professor e o espaço do aluno que não permite muita aproximação entre esses dois. Dessa forma, podemos dizer que a Classificação também é forte $(\mathrm{C}+)$. 
Quadro 2 - Contexto Regulador (DR)-Regras hierárquicas quando os alunos fazem perguntas

\begin{tabular}{|c|c|c|c|c|}
\hline \multicolumn{5}{|c|}{$\begin{array}{l}\text { Contexto regulador (DR) - Regras hierárquicas } \\
\text { Relação entre sujeito: professor-aluno }\end{array}$} \\
\hline Indicador & $\mathbf{E}++$ & $\mathbf{E}+$ & E- & E- - \\
\hline $\begin{array}{l}\text { Quando os alunos } \\
\text { fazem perguntas }\end{array}$ & $\begin{array}{c}\text { Ignora as perguntas } \\
\text { dos alunos e } \\
\text { continua sua } \\
\text { explanação. }\end{array}$ & $\begin{array}{c}\text { Responde } \\
\text { diretamente ao aluno } \\
\text { que formulou a } \\
\text { pergunta. }\end{array}$ & $\begin{array}{c}\text { Responde } \\
\text { formulando } \\
\text { perguntas e } \\
\text { fornecendo algumas } \\
\text { informações, } \\
\text { ajudando o aluno } \\
\text { a encontrar a } \\
\text { resposta. }\end{array}$ & $\begin{array}{c}\text { Responde, } \\
\text { promovendo a } \\
\text { discussão entre } \\
\text { os vários alunos } \\
\text { e a professora até } \\
\text { chegarem a uma } \\
\text { resposta. }\end{array}$ \\
\hline \multicolumn{5}{|c|}{$\begin{array}{l}\text { Episódio } 1 \text { do dia } \mathbf{0 3 / 0 4 / 2 0 1 8} \\
\text { 1.Aluno: Oh, professor, as células ficam em que parte do corpo? } \\
\text { 2. Professor: Pensa aí e responde para mim... Fala aí. } \\
\text { 3. Aluno: É onde? } \\
\text { 4. Professor: Hum? } \\
\text { 5. Aluno: É onde? } \\
\text { 6. Professor: Você acha que fica onde a célula? Hein? Fala aí, com sinceridade, Rafael. Você pensa que a célula do } \\
\text { nosso organismo está onde? Não tem nem ideia? } \\
\text { 7. Aluno: Não sei... } \\
\text { 8. Professor: Seu organismo todinho é formado por inúmeras células, entendeu? Bom... A célula também é a } \\
\text { unidade reprodutora }[\ldots] \text {... }\end{array}$} \\
\hline
\end{tabular}

Fonte: Pesquisa direta da autora, 2018.

Quando os alunos fazem perguntas ao professor durante a explanação da sua aula, Antônio responde diretamente ao discente que lhe formulou a questão. De acordo com o episódio, ele parece se zangar com a pergunta do aluno, uma vez que já foi explicado o conteúdo de células para a turma. O professor não envolve toda a sala na explicação dos conteúdos ou abre o tema para discussão, como sugere Morais e Neves (2003), em relação à Pedagogia Mista, que valoriza um ambiente aberto de comunicação entre professor-aluno em que o discente possa perguntar e trocar ideias a fim de que o aprendizado ocorra. Dessa forma, com base neste episódio, podemos caracterizar a prática pedagógica do professor com um grau de enquadramento forte $(\mathrm{E}+)$.

Quadro 3 - Contexto Regulador (DR)- Regras hierárquicas perante os comportamentos não legítimos

\begin{tabular}{|c|c|c|c|c|}
\hline \multicolumn{5}{|c|}{$\begin{array}{c}\text { Contexto regulador (DR) - Regras hierárquicas } \\
\text { Relação entre sujeito: professor-aluno }\end{array}$} \\
\hline Indicador & E++ & E+ & E- & E- - \\
\hline $\begin{array}{c}\text { Perante os } \\
\text { comportamentos não as razões } \\
\text { legítimos }\end{array}$ & $\begin{array}{c}\text { O professor irrita-se } \\
\text { utilizando controle } \\
\text { imperativo. }\end{array}$ & $\begin{array}{c}\text { O professor chama } \\
\text { a atenção dos } \\
\text { alunos recorrendo a } \\
\text { apelos de natureza } \\
\text { posicional. }\end{array}$ & $\begin{array}{c}\text { O professor chama } \\
\text { a atenção dos } \\
\text { alunos recorrendo a } \\
\text { apelos de natureza } \\
\text { posicional ou } \\
\text { pessoal. }\end{array}$ & $\begin{array}{c}\text { estes justificam seus } \\
\text { comportamentos } \\
\text { ilegítimos e discute } \\
\text { essas razões } \\
\text { utilizando um } \\
\text { controle pessoal. }\end{array}$ \\
\hline
\end{tabular}


Episódio 1 do dia 03/04/2018

1. Professor: Então, o que acontece... Vocês ficam aí fazendo bullying com o colega, está vendo?

2. Professor: Oh, gente, para com essas brincadeiras, vocês já são adultos... Essas brincadeiras não levam a lugar nenhum. Então, olha só, retomando aqui... A nutrição celular é um ambiente capaz que a célula tem para ela se manter e para ela conseguir desenvolver as funções. Imagina aí, pensa aí na gente sem as refeições, sem nossa alimentação. Não tem como, não é verdade?

Episódio 2 do dia 17/07/2018

1. Professor: Aqui, os meninos! É por isso que vocês não entendem, ó! Por isso, não entendem! Eu estou explicando, eu sei que é chato, mas se você entender aqui uma vez, você pega o assunto! E ano que vem vocês vão ver esse conteúdo de novo em Química, você vai chegar ano que vem, e vão ver isso de novo na matéria de Química com mais profundidade, mais aprofundado. Então, se a pessoa aprender agora, já está com meio caminho andado, está estudando a matéria do ano que vem. Então, olha só! Esse elemento químico, ele tem 27 elétrons! Dois desses 27 estão na camada K, 8 está na L, formou 10, né? Ainda sobraram quantos? 17.

2. Aluno: Libera mais cedo?

3. Professor: Pessoal, vamos aprender isso aqui, porque se não aprender hoje na próxima aula eu vou voltar com isso e vou passar um exercício. Aí vai ter que parar a aula, começar tudo de novo, para reexplicar isso aí. Aprende logo e fica livre!

Fonte: Pesquisa direta da autora, 2018.

O professor Antônio mantém uma postura firme de ordem em relação aos comportamentos não legítimos ${ }^{6}$. Podemos perceber, ao decorrer das observações, que ele é muito respeitado pelos discentes, mas não permite brincadeiras inapropriadas, deixando explícita sua posição de poder e autoridade em sala. Nesse sentido, classificamos a prática do professor com um grau de enquadramento forte $(\mathrm{E}+)$.

\section{Resultado da caracterização da prática do professor}

As observações e anotações em diários de campo contribuíram para a caracterização das diversas relações que definiram a prática pedagógica do professor de Ciências. Quando analisamos a relação entre as características sociológicas que definem o contexto regulador, os resultados mostraram que a prática docente analisada assume uma configuração de controle fortemente centralizada no professor, compatível com uma Pedagogia Visível.

Observamos um enquadramento forte nas Regras Hierárquicas e uma classificação também forte entre os espaços entre professor-aluno, evidenciando, assim, um afastamento do modelo proposto pela Pedagogia Mista, que prevê um enfraquecimento do enquadramento, tanto ao nível das Regras Hierárquicas quanto da classificação ao nível das relações entre espaços. De acordo com Morais e Neves (2003), esse enfraquecimento parece ser mais favorável à aprendizagem dos alunos - que teriam acesso e oportunidade de discutir as explicações dos conteúdos curriculares realizadas pelos professores e terem voz nessa relação.

\footnotetext{
$\overline{6}$ Comportamento não legítimo pode ser entendido como indisciplina.
} 


\section{Considerações finais}

A teoria bernsteiniana auxiliou-nos a desvelar o currículo de Ciências materializado nas práticas pedagógicas de um docente da educação de jovens e adultos. Tomando por base o referencial teórico de Bernstein (1996), em relação às Regras Hierárquicas, o discurso do professor é predominante e a classe é tratada como homogênea.

Os dados construídos por meio da observação das aulas e entrevistas com o professor de Ciências permitem afirmar que sua prática pedagógica assume a configuração de uma pedagogia visível, em que o controle e gestão da turma estão fortemente centralizados na figura do professor, que é facilmente identificado. Esse tipo de pedagogia também produz estratificação entre os alunos. Há por parte do docente uma individualização da aprendizagem, isto é, recebe maior atenção os estudantes que participam da aula. Nessa situação, entram em jogo as regras criteriais, ou seja, os alunos que satisfizerem os critérios previamente definidos obterão sucesso. Isso entra em desacordo com a proposta curricular do campo recontextualizador oficial do Programa Tempo Juvenil.

Em nenhum momento o professor fez uso do livro didático para o Tempo Juvenil, nem apostilas ou experimentos que poderiam tornar as aulas com outro nível de exigência conceitual. As aulas observadas foram, na maioria das vezes, expositivas. Embora o professor tenha feito uso de vídeo como recurso didático para a turma 4A, não houve a exploração do recurso de forma a fomentar uma discussão sobre o tema, ou seja, o recurso não contribuiu para aumentar o nível conceitual dos alunos.

\section{Referências}

BAHIA. Secretaria de Educação. Proposta Pedagógica do Tempo Juvenil / Ensino Fundamental para estudantes de 15 a 17 anos. Salvador: Secretaria Estadual de Educação, 2013.

BRASIL. Instituto Nacional de Estudos e Pesquisas Educacionais Anísio Teixeira (INEP). Ideb, 2017. Brasília: MEC, 2017.

BERNSTEIN, B. A estruturação do discurso pedagógico. Classe, códigos e controle. Petrópolis: Vozes, 1996.307 p.

BOGDAN, R. C.; BIKLEN, S. K. Investigação qualitativa em educação: uma introdução à teoria e aos métodos. Portugal: Porto Editora, 1994.

DINIZ, P. Materiais curriculares educativos e professores que ensinam Matemática: mensagem, recontextualização e identidade pedagógica. Tese (Doutorado em Educação). Faculdade de Educação, Universidade Federal da Bahia, Salvador, 2017.

EUGENIO, B. Práticas curriculares em uma escola de ensino médio no Estado da Bahia. Educação, Santa Maria, v.42, n.1, p.57-72, 2017.

GALLIAN, C.V.A. A prática pedagógica e a criação de um contexto favorável para a aprendizagem de ciências no Ensino Fundamental. Ciência \& Educação, v. 18, n. 2, p. 419-433, 2012. 
GALLIAN, C.V.A. A recontextualização do conhecimento científico: os desafios da constituição do conhecimento escolar. Tese (Doutorado em Educação). Faculdade de Educação, Pontifícia Universidade Católica de São Paulo, São Paulo, 2009.

GRILO, J.S. P. Da universidade para a escola: a recontextualização de princípios e textos do discurso pedagógico de disciplinas específicas da licenciatura em Matemática. Dissertação (Mestrado em Educação). Faculdade de Educação, Universidade Federal da Bahia, Salvador, 2014.

LEÃO, G. M. P. Políticas de juventude e Educação de Jovens e Adultos: tecendo diálogos a partir dos sujeitos. In: SOARES, L.; GIOVANETTI ,M. A.; GOMES, N. L. (Orgs.). Diálogos na Educação de Jovens e Adultos. 3.ed. Belo Horizonte: Autêntica, 2007.

LÜDKE, M.; ANDRÉ, M. E. D. A. Pesquisa em educação: abordagens qualitativas. São Paulo: EPU, 1986.

MAINARDES, J. Reinterpretando os ciclos de aprendizagem. São Paulo: Cortez, 2007.

MORAIS, A. M; NEVES, I. P. Processos de intervenção e análises em contextos pedagógicos. Revista Educação, Sociedade e Cultura, v. 19, p.49-87, 2003.

MORAIS, A. M. Poder e controlo na sala de aula: Definição teórica de modalidades diferenciais de prática pedagógica. In: MORAIS, A.M.; NEVES, I. P. (Orgs.). Socialização primária e prática pedagógica II: Análise de aprendizagens na família e na escola. Lisboa: Fundação Gulbenkian, 1993.p. 15-85.

PIRES, D.M. Práticas pedagógicas inovadoras em educação científica: Estudo no $1^{\circ}$ ciclo do ensino básico. Tese (Doutorado em Ciências da educação). Faculdade de Ciências da Universidade de Lisboa, Lisboa, 2001.366 p.

PIRES, D.; MORAIS, A. M.; NEVES, I. P. Desenvolvimento científico nos primeiros anos de escolaridade Estudo de características sociológicas específicas da prática pedagógica. Revista Portuguesa de educação, v. 12, n. 2, p. 129-132, 2004.

SANTOS, L.L.C.P. Bernstein e o campo educacional: relevância, influências e incompreensões. Cadernos de Pesquisa, n. 120, p. 15-49, 2003.

SILVA, R. L.; SOUZA, G. M.; SANTOS, B.F. Questionamentos em aulas de Química: um estudo comparativo da prática pedagógica em diferentes contextos sociais. Revista Brasileira de Pesquisa em Educação em Ciências, v.18, n.01, p.69-96, 2018.

Recebido: 10/03/2019

Aprovado em: 08/09/2019 